\title{
Exploring Chinese consumers' attitudes toward traceable dairy products: A focus group study
}

\author{
Shalamujiang Maitiniyazi ${ }^{1,2 *}$ and Maurizio Canavari ${ }^{2}$ \\ ${ }^{1}$ Department of Economy and Trade, Xinjiang Agricultural University, No. 311 Nongdadonglu, Urumgi City, 830011, Xinjiang, P. R. China \\ ${ }^{2}$ Department of Agricultural and Food Sciences, Alma Mater Studiorum - University of Bologna, Viale Giuseppe Fanin 50, I-40127, Bologna, Italy
}

\begin{abstract}
Dairy products are an essential part of a healthy diet, and dairy is an emerging food industry in China. With rapid economic development, Chinese consumers are increasingly health-conscious and are becoming more selective about the quality and safety of dairy products. Adopting a qualitative approach, we explored Chinese consumers' perception of dairy food safety and attitudes toward traceable dairy products through 9 focus group interviews administered in 4 urban locations in North and South China, with a total of 61 participants. Results showed that a prevalence of food safety incidents triggers consumers to lower their confidence in food safety and to pay more attention to the news about food safety incidents in the media, including social media. Chemical residues ranked as the first concern for food safety in the dairy industry. Meanwhile, traceable dairy products were not well known among consumers. Although the possibility to trace back all stages of the food supply chain in the dairy sector was considered important, respondents raised doubts about the truthfulness of traceability information.
\end{abstract}

Key words: dairy products, food traceability, consumer perception, focus group

\section{INTRODUCTION}

Dairy products are essential components of the diet, and there has been an upsurge in consumption worldwide, especially in developing countries (Handford et al., 2016). The dairy industry in China is new, with much development potential as part of China's food industry, also thanks to strong government support (Wu et al., 2018). As the developing country with the largest population, there is a great demand for dairy products in China. According to forecasts, 2018 consumption of

Received February 22, 2020.

Accepted June 30, 2020.

*Corresponding author: maitini.shalamujiang@unibo.it milk was expected to reach 41 million tons, about $9.5 \%$ more than in 2017 (Ward and Inouye, 2018). However, with the rapid development of the dairy industry in China, many concerns about safety and quality management have arisen. Dairy quality and safety have emerged as crucial issues because food safety incidents occur more frequently in this supply chain (Ding et al., 2018; Song et al., 2018), thus causing consumers to lose their confidence in the dairy industry.

To reduce food safety risks and prevent serious food safety incidents, as well as enhance consumer confidence in food safety, the Chinese government has undertaken various policy measures to improve the safety and quality of dairy products in recent years. Establishing a food traceability system is one of the top policy tools to attain this goal (Zhang et al., 2012); however, traceability is not mandatory for all suppliers in the dairy industry in China, but only for infant formula milk powder.

Implementation of traceability systems could lead to higher production and distribution costs, and thus to higher prices of products, and price perception would directly influence demand and customer satisfaction. On the other hand, it may lead consumers to perceive a higher value and be willing to pay a premium price for dairy products; therefore, firms working in the food business have to compare potential benefits and costs.

It is important to understand consumers' awareness of the quality and safety of dairy products, their purchasing behaviors, and their attitudes toward traceable dairy products in order to implement food traceability system in the dairy industry. Furthermore, it is necessary to know consumers' perceptions of the authenticity of traceability information.

Driven by frequent food safety incidents, a large number of studies on Chinese consumers' perception and behavior for dairy products have been carried out. Chinese consumers' perception of certified dairy products has received increasing attention by scholars due to increasing concern among consumers about food safety (Wang et al., 2008; Quan et al., 2011; Xu et al., 2016). Indeed, Chinese consumers are concerned about 
the safety and quality of the dairy products they consume (Qiao et al., 2010). Some previous studies have emphasized the demographic characteristics that could affect their risk perception of dairy products; specifically, family income significantly affects a consumer's milk safety concerns (Xu et al., 2010). Wu et al. (2014) reported that most Chinese consumers had a lack of knowledge of organic food but had a higher willingness to pay for EU and US infant milk formula with organic certification labels. They also found that, in addition to the price factor, the organic certification label, brand, and country of origin are the most important attributes for consumers purchasing infant milk formula. In another study, young females with a strong educational background have expressed a high safety concern and have the strongest consumption desire for organic milk, and those who shop for the family tend to support organic milk and are willing to pay more for it (Xu et al., 2016).

Some studies specifically aimed to examine consumers' attitudes toward traceable dairy products. Consumers are generally willing to pay higher prices for infant formula with traceable labels and generally do not approve sales in pharmacies (Zhu and $\mathrm{Xu}, 2017$ ). Traceability information was more important than brand or country of origin for Chinese consumers purchasing infant milk formula (Yin et al., 2017). A study by Yin et al. (2017) based on the analysis of policy background, analyzed consumers' willingness to pay to examine the effects of public management policy through choice experiments. The research showed that consumers had a higher willingness to pay for infant milk formula with traceable information labels, famous brands, and overseas production. Bai et al. (2013) indicated that consumers significantly prefer traceable milk products to those carrying no traceability information.

Although the importance and perceived value of traceability information for dairy products has been established, to the best of our knowledge, no research has used a qualitative approach to study attitudes of consumers toward traceable dairy products. The absence of qualitative studies may lead to a lack of indepth understanding of the issue at hand; quantitative studies may have been designed considering only the researchers' view, thus missing important aspects of the problem. This study aims to address this gap, providing a more comprehensive insight into Chinese consumers' attitudes toward traceable products, although with the typical limitations of a qualitative approach.

The research questions to be addressed here are:

- What are the Chinese consumers' perceptions of food safety in the dairy sector?
- What attitudes do Chinese consumers have toward traceable dairy products?

- What are Chinese consumers' attitudes toward traceability certification authorities?

This research aims to explore Chinese consumers' perception of dairy food safety and purchasing behavior related to dairy products, as well as to analyze consumer attitudes toward traceability systems and traceable dairy products through a qualitative approach. The objectives of this paper are to explore consumers' perceptions of food safety of dairy products and to investigate consumer attitudes and perceptions toward traceability in the dairy industry.

As an exploration, the purpose is to highlight notable issues and to provide insights that, although they cannot be generalized and must be considered with care, may serve as a useful input for further research. We aim to provide a useful contribution and possible starting point for more in-depth qualitative and quantitative analyses on this crucial topic.

\section{MATERIALS AND METHODS}

Many methods are available for consumers attitudes and perceptions, such as individual interviews, focus groups, nominal group technique, concept mapping, and the Delphi method. (Powell and Single, 1996; Hasimu et al., 2017; Su and Canavari, 2018). Each qualitative technique has advantages and disadvantages that make them more or less suitable to achieve the research goals (Morgan and Krueger, 1993; Morgan, 1996).

Among the qualitative techniques available, we identified focus group interviews as the most appropriate method for this study, due to the ability to stimulate the participants' reactions to new information as they are expressing their thoughts (Crovato et al., 2019). In-depth interviews allow the researcher to have a very intense exchange of information with the subject and are suitable when dealing with sensitive or confidential information. Focus groups, on the other hand, are more efficient and enable researchers to identify quickly the full range of perspectives held by the participants in the group discussion. In focus groups, participants can clarify or expand upon their opinions in light of points raised by other participants, thus considering elements that might be ignored or left underdeveloped in in-depth interviews (Powell and Single, 1996). A distinctive feature of focus groups is that data is generated through social interaction; the researcher can take advantage of group dynamics and interactions between participants, which allows for a better observation of consensus and disagreements between individuals (Belk 


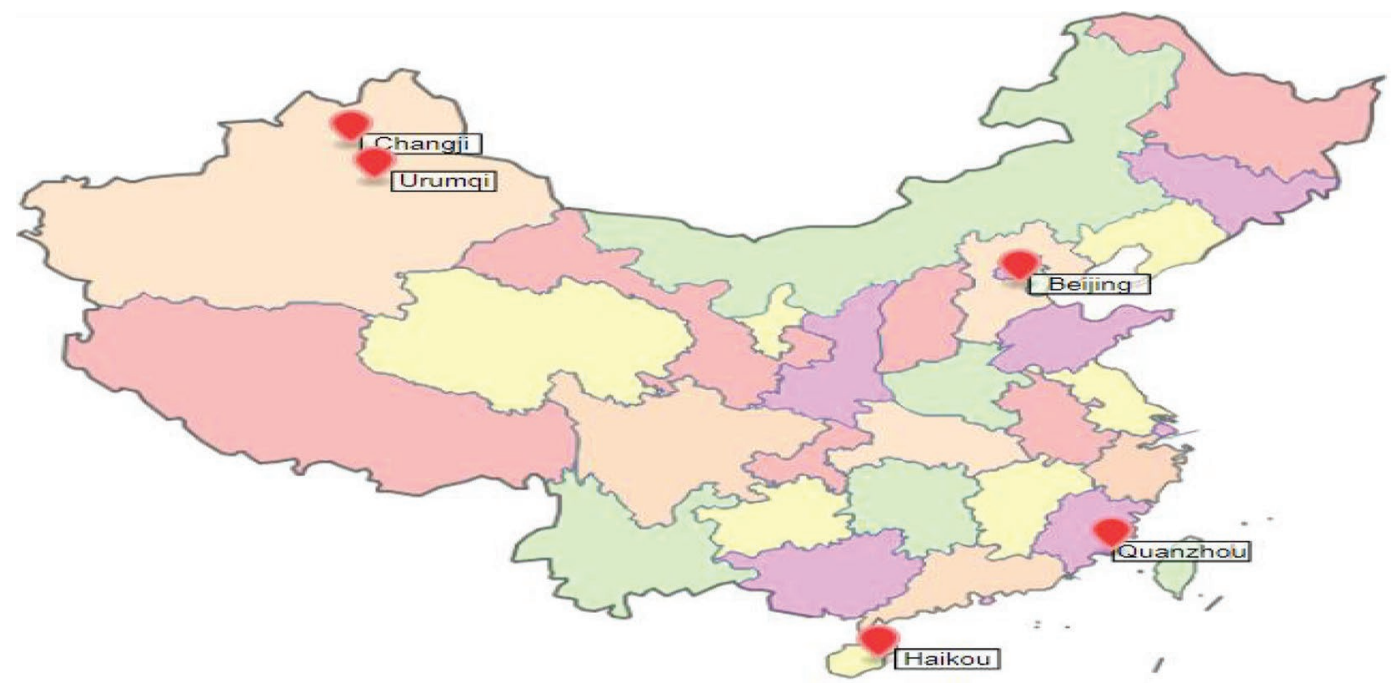

Figure 1. The map shows the focus group locations: Urumqi and Changji in Northwest China and Haikou and Quanzhou in South China.

et al., 2013). Consumer focus groups are suitable to efficiently explore several experiences and ideas of the participants, allowing them to interact, stimulate each other, and compare their views, which helps the researcher gather insight about the group's feelings (Morgan and Krueger, 1993; Morgan, 1996; Threlfall, 1999).

The same method has been used in the study of consumers' perception in food markets in China or other countries (Williams et al., 2005; Asioli et al., 2014; Bruschi et al., 2015; Cui et al., 2016; Roos et al., 2016; Lindberg et al., 2018; Hinkes and Christoph-Schulz, 2019; Kendall et al., 2019).

\section{Focus Group Procedure}

Interview guidelines were defined based on the literature review and organized in 3 sections. In the first section, participants were asked to give their opinion relating to food safety concerns. In the second section, consumers were asked about their purchasing behavior and food safety perception of dairy products. The last section led the group into discussions about consumer attitudes toward traceable dairy products and the actors in the food traceability system.

Each focus group interview lasted approximately 90 min; before starting the interview, participants were provided with the interview guidelines. The participants were told to discuss 3 categories of dairy products: milk, yogurt, infant formula milk powder.

The data for the study were collected during 9 focus group interviews, a number that is higher than most similar studies based on this method (Nyumba et al., 2018); this number results from both time and budget constraints and from the consideration of the emer- gence of information from the new focus groups (Guest et al., 2017).

Geographically, data were collected in 4 cities (Figure 1): Urumqi and Changji in Northwest China (North group), and in Haikou and Quanzhou in South China (South group). Urumqi and Changji belong to the Xinjiang Uygur Autonomous Region (Xinjiang). Urumqi is the capital city of Xinjiang, which is an important highquality milk source and significant production area of dairy products in China. Haikou is the capital and the most populous city of the Hainan province, and Quanzhou is the largest metropolitan region in the Fujian province, where its gross domestic product ranked first in the province from 1991 to 2010. To a certain extent, Haikou and Quanzhou are representative of the coastal regions of South China.

The focus groups were conducted from January to April 2018. Altogether, 61 consumers (24 male, 37 female) of dairy products participated in the focus group interviews. Three focus group sessions were held in Changji, and 2 sessions were held in each of the other locations.

Most scholars using focus group interviewing recommend a group size of 6 to 12 people. If there are more than 12, the session takes too long, and group interaction becomes more difficult to achieve; if there are fewer than 6, there may be insufficient interaction (Lichtman, 2014). Consistent with best practice, each focus group in our study contained 6 to 9 participants recruited based on selection criteria aimed at achieving a balance for demographic characteristics and purchasing habits, specifically sex ( $40 \%$ males and $60 \%$ females), age (18-60 yr), education background, socioeconomic status (middle or upper class), and purchase of dairy 
Table 1. Focus group participants' characteristics

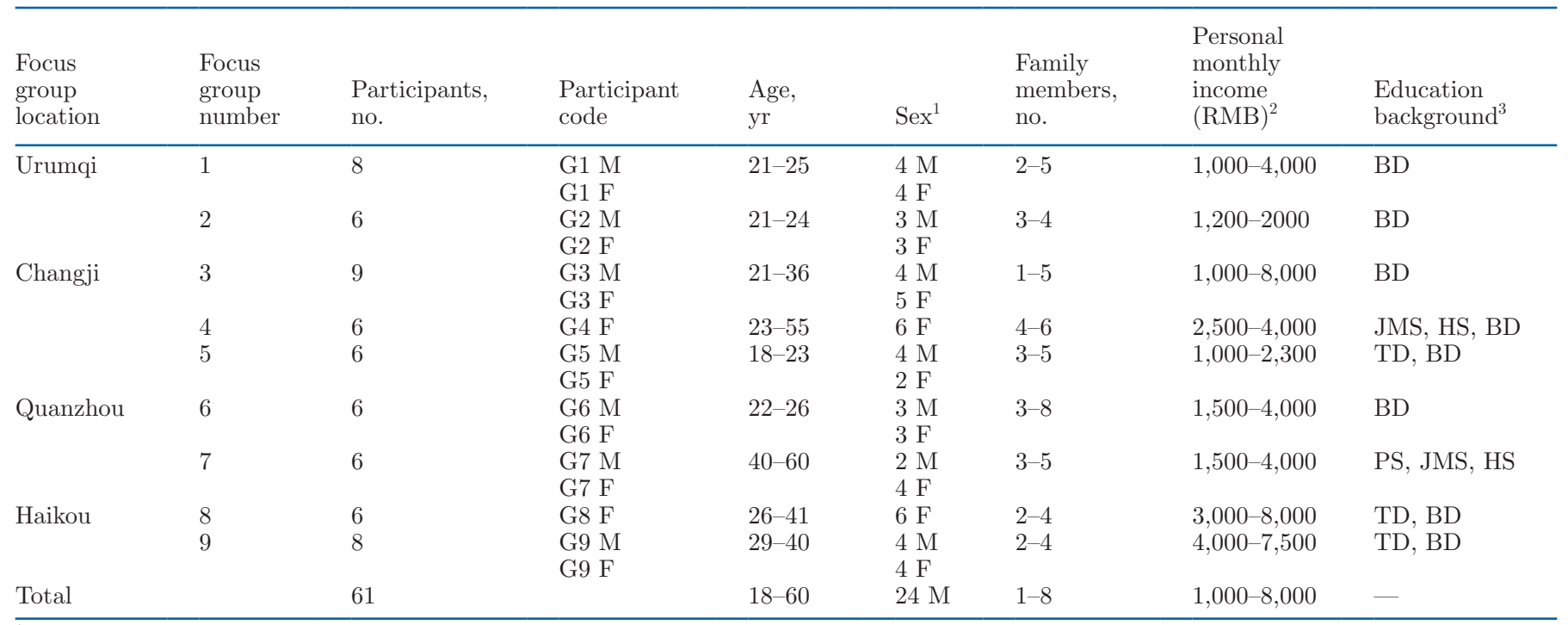

${ }^{1} \mathrm{M}=$ male; $\mathrm{F}=$ female.

${ }^{2}$ Foreign exchange quotation is US $\$ 100=682.83$ Yuan (October 16, 2018). RMB = renminbi/Chinese Yuan.

${ }^{3} \mathrm{PS}=$ primary school; JMS = junior middle school; HS = high school; TD = technical or vocational degree; BD = bachelor's degree.

products in the last 3 mo. Participants in peer groups were invited to the same group for discussion to reduce heterogeneity among participants in our focus groups. The final composition of the groups is summarized in Table 1. Except for group 4, participants in other groups were mostly in the same peer groups.

\section{Data Analysis}

The participants' agreement to take part in the focus groups was based on fully informed consent; all participants are anonymized. All of the focus group discussions were recorded and transcribed verbatim by 2 research assistants managing the interviews and checked by the first author and a master's degree candidate to ensure consistency. Data input and analysis were carried out using the software Nvivo version 11.4.0 for Windows (QSR International Pty Ltd., Melbourne, Australia), which has features such as character-based coding, rich text capabilities, and multimedia functions that are crucial for qualitative data management (Zamawe, 2015). The first author read and re-read the verbatim text and then carried out the open coding. The interview guide covered the following topics: (1)

Table 2. Interview guidelines

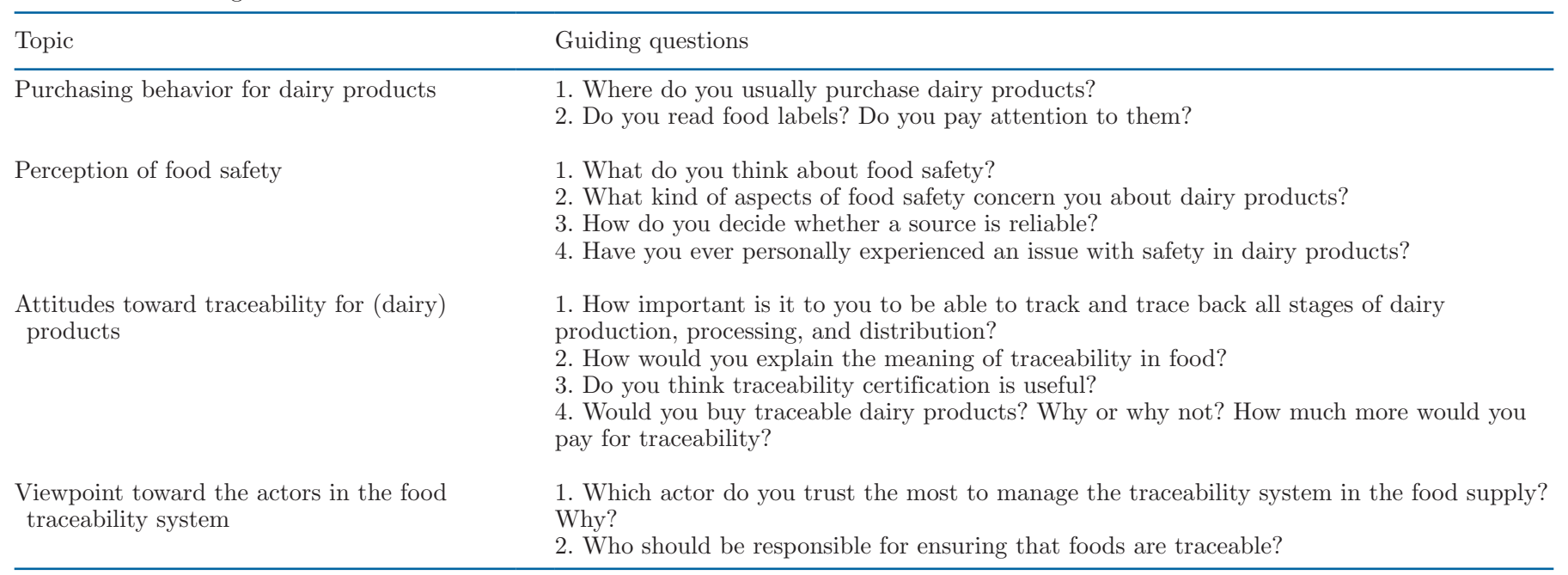


purchasing behavior for dairy products, (2) perception of food safety in the dairy sector, (3) attitude toward traceability of dairy products, and (4) perception of the actors in the food traceability system (Table 2). The full discussion guidelines are available from the authors on request.

\section{RESULTS}

\section{Purchasing Behavior}

Participants reported the supermarket was the primary place to purchase dairy products because they are perceived as more convenient, and they also offer many opportunities to select and buy a safe product. This preference was stronger among the participants in groups from the South.

A large number of participants chose the large retailers such as Carrefour or other supermarket chains as the most frequent purchasing venue for dairy products. Some participants in North groups purchase loose milk in small retail shops, convenience stores, or from street vendors. The consumers think that the loose milk sold there is safer and cheaper because they trust that these products are very fresh and without food additives.

Concerning label information, with a few exceptions, most of the respondents stated that they have a habit of reading the label information when buying dairy products. Nevertheless, the results from the discussion show that the respondents from different groups pay attention to different pieces of information on the labels of milk and yogurt products. Most of the respondents in the North group indicated that they pay the most attention to the production and expiration date, whereas the brand and production dates are critical information for respondents in the South group when buying milk and yogurt.

\section{Food Safety Concern}

The majority of participants reported that they were worried or very worried about the safety of dairy products. Food safety incidents were mentioned frequently, which resulted in many consumers turning to imported dairy products for safety and quality.

The results from that discussion showed that consumers who live in different areas have a different perception of food safety in the dairy industry. As expected, participants in the North group stressed the fact that they are concerned about food safety issues, but they also expressed more optimistic views about food safety than participants in the South group. The main reason for that could be the region in which they live-Xinji-

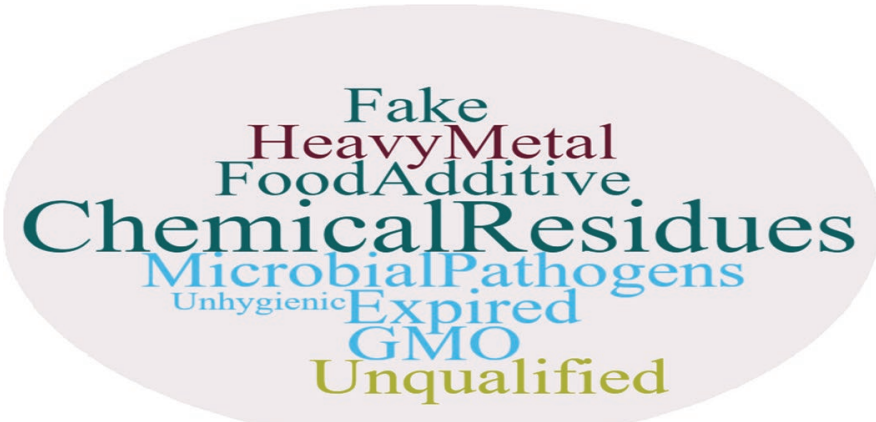

Figure 2. A word cloud shows the concerns about dairy product safety mentioned by the focus group participants.

ang is 1 of the 5 traditional pasturing areas and one of the most important milk sources of China. Participants in the North group consistently expressed higher confidence in food safety of dairy products, mainly because they feel assured by the local origin of the product and the reputation of the area for specialized livestock farming. Participants who have older people or children (under 16 yr old) in their family expressed more concern about food safety and quality in the dairy sector, because they pay close attention to food safety when they prepare food for their children or parents.

The answers collected from the discussion about dairy product safety are graphically depicted in Figure 2 using a word cloud. It is a visual representation of text data, widespread for reporting qualitative data (Cappelli et al., 2017); the most frequent words appear to represent participants' concerns in the dairy sector. From the data in Figure 2, it is apparent that the respondents had a great concern for chemical residues, followed by food additives and microbial pathogens as the top 3 concerns. More than half of the participants mentioned chemical residues during the discussion, whereas other participants replied that they also worried about expired food and heavy metal pollution with dairy products.

\section{Influence of Social Media on Consumers' Perception}

Media coverage plays an essential role in people's food-risk perceptions following a major food scare, as media perspectives on the safety of the food supply might have an effect on those of the general public (Zingg et al., 2013). Participants gave many examples of cases of food safety incidents that have been reported in the media, such as Sudan red and the melamine milk scandal. Sudan I is a synthetic-azo dye commonly used to adulterate foods to increase sensory appearance; however, it is banned due to its carcinogenic, mutagenic, 
and genotoxic properties, which represent a serious risk to human health (Giselle et al., 2020). The melamine milk scandal happened more than 10 years ago, and although consumers' confidence has been restored in the safety of dairy products, some of them have not forgotten it, and this chemical contamination scandal left many families worried about dairy products.

Personal or relatives' experience with food safety is another major factor affecting consumers' perception. Fifteen participants out of 61 replied that they or their relatives had direct experience with food safety issues.

\section{Tracking and Tracing Dairy Products}

Most of the participants expressed that tracking and tracing the stages of dairy production, processing, and distribution is of utmost importance. They believe that traceability at all stages (from farm to table) can provide information that they want to know and will help them make the right purchasing choices. Meanwhile, some are worried about the reliability of tracking and tracing product information. They are especially worried about the fact that enterprises might falsify traceability information for their commercial interests.

In contrast, only few participants perceived traceability as unimportant. In this regard, some participants stated that traceability information would help authorities figure out where the problem began. It has been perceived almost as a relief measure, and it may not improve food safety.

The results of the section on consumers' awareness indicated that most respondents do not know much about traceable food. Some of them had heard about it before, and a small number of respondents expressed that they had purchasing experience. Interestingly, although some had not heard about traceable food before, they could explain the concept. The reason may be imputable to semantics: in the Chinese language, the word ke zhui su explicitly describes the concept of traceable; it literally means "the ability to trace back," so consumers can easily guess the meaning.

However, having awareness about the traceability of products does not necessarily equate a full understanding of traceable food. When asked about the difference between traceable and untraceable food, they stated that with traceable food, one could trace back the production information (i.e., the place and date of production or producer information). They thought traceability included only product information. However, according to the definition given by the Codex Alimentarius Commission Procedural Manual (FAO/ WHO, 1997) traceability is "the ability to follow the movement of a food through specified stage(s) of production, processing and distribution" (Olsen and Borit, 2013). It is obvious most of the participants were not fully aware of the food traceability system features.

\section{Traceability Labeling and Consumer Confidence}

Although half of the participants did not know about traceable food, after the investigators gave a brief video introduction, 5 out of the 6 participants believed that the food traceability system will be valuable to them. For them, it could enhance their confidence in food safety when purchasing dairy products. Participants explain that:

"I think the traceable label is useful because traceability of information will be valuable to both enterprises and consumers. The enterprises can ensure the reliability of the source of the raw materials through a traceability information process. Meanwhile, consumers also have to be able to check processing information." (Group 1, woman, 21 yr old)

"I like the system as it allows me to decide whether to buy the dairy product by tracking and tracing back all of the stages of processing or production information." (Group 2, man, 23 yr old)

However, some participants reported that the system is not useful for them, or they do not know whether it is useful to them. Their main reason is that the food traceability system is an ex post measure, which can provide only the tracked information and allows only for timely recall of the suspected products along the food supply chain in the event of food safety problems. It could help the government or enterprises determine who should be responsible for such problems. Furthermore, they were also worried about the reliability of the tracked information. Most participants said they had not bought traceable dairy products before; however, after the investigators gave a brief video introduction, some participants stated they had consumed traceable milk without knowing it was called traceable milk.

We also asked about the extra charges for traceable dairy products and the reasons that participants do or do not buy the traceable dairy products. The results showed that most respondents are willing to bear less than $10 \%$ extra cost for traceable dairy products. It was evident that the premium consumers were willing to pay was not high. In the supermarket, the price of traceable foods is much higher than those of nontrace- 
able foods ( $\mathrm{Wu}$ et al., 2012). The results also showed that health benefits are an essential motive for the purchase of traceable dairy products. The main reasons for not being willing to buy were given as incomprehension, distrust, inconvenience to purchase, and price.

\section{The Role of Supply Chain Operators: Trustworthiness of Traceability Information}

In our interviews, participants indicated that they suspected the authenticity of traceability information. They were more likely to trust the traceability information certified by the government, followed by thirdparty certified or internationally certified information. Most of them do not trust the traceability information provided by the producing company that has not been certified by a third-party certification body. They worried enterprises might falsify traceability information for their commercial interests. However, some interviewees stated that the traceability information certified by the domestic third-party or international agencies is valued more highly than certificates issued by the government or enterprises. Participants explained this by saying:

"I trust more in traceability information certified by the professional third-party agencies rather than certified by the government, because the former is more professional and more reliable." (Group 8, woman, 30 yr. old)

"I think the government does not place enough emphasis on the food traceability system yet; I have a lack of trust in the traceable information on certified products carried out by the government. In contrast, the domestic third-party or international agencies certificate for traceability has more value for me, because they are more professional." (Group 1, woman, 23 yr old)

Another issue worth discussing is the fact that participants who trusted government certificate or third-party agencies certificate have in common a lack of faith in enterprise certificate. They worried that the enterprises might falsify traceability information for their commercial interests. For example, a man, 40 yr old, said:

"Enterprises focus more on their commercial interests. The traceable information certified by food enterprises itself is quite unreliable, and the traceability information provided by enterprises itself that are not certificated by any third-party bodies, whether it is a third-party agency or government, has no value for me."

\section{Who Should Cover the Cost?}

Implementation of traceability systems could lead consumers to perceive a higher value and to be willing to pay a premium price for dairy products. However, traceable food with relatively complete production attributes is bound to have a higher production cost, which will be eventually reflected by the product price, and consumers will have to make trade-offs between traceability and higher prices for traceable food (Wu et al., 2017). Participants discussed who should be responsible for the cost of the food traceability system. Most of the participants stated that the government should be responsible for all or most of the cost of establishing the food traceability system. A participant explains that:

"I think food safety is the government's legal responsibility, and the government should ensure the safety and quality of the foods that were sold in the market. In this regard, the government should bear the most responsibility for this cost because if they let enterprise pay most of the cost, I am afraid they may falsify the traceability information to save money. On the other hand, consumers will pay the cost, which should be undertaken by the enterprise." (Group 1, woman, 22 yr old)

However, some other participants reported that enterprises should bear all the cost for establishing the food traceability system, and a few participants stated that consumers should pay for it.

\section{DISCUSSION}

\section{Purchasing Behavior}

The results showed that most participants regard supermarkets as the primary place to buy dairy products. One of the reasons for that is that the customers perceive convenience, proximity, variety, and food safety as very important to them. Similar to the results offered by Cheng et al. (2016), supermarkets were the purchasing places most trusted by customers. Some participants in North groups said they would purchase loose milk in the small retail shops such as a convenience store or from street vendors. They think loose milk sold there is safer and cheaper because they are convinced the dairy products are very fresh and without food additives. Our study confirms the previous finding that the main factors leading Chinese consumers to select street vendors to purchase foods are convenience, freshness, and price. Street vendors have large numbers of customers 
because they are highly convenient, and generally, they tend to offer lower prices (Feng et al., 2012).

Our findings show that most participants have the habit of reading the label information when buying dairy products. Consumers noted reading food labels could help them obtain more information and make a good choice to purchase. This finding is in line with a previous study conducted by Qing et al. (2006), which revealed that a vast majority of consumers in Wuhan city claimed to read the information on food labels or production descriptions before making a purchase decision. However, this finding significantly differs from previous results reported in the literature (Wang et al., 2013; Zhu et al., 2013; Chan et al., 2016). Our interviewees expressed the opinion that brand and quality certification got the most attention from them when purchasing infant formula milk powder. The respondents from different groups have different attention to the label's information during purchases of milk and yogurt products. Most of the respondents in the North group have indicated that they pay the most attention to the production and expiration date, whereas the brand and production date is the key information for respondents in the South group when buying milk and yogurt.

\section{Consumers' Food Safety Concerns}

Food safety consistently ranks among the top concerns of participants in the discussion. The outcome of this discussion is not surprising. To enhance consumer confidence in food safety, the government has undertaken various policy measures to improve the safety and quality of food. However, Chinese consumers are concerned about the quality and safety of their food, as are consumers in other countries, and indeed the Chinese consumers have more reason to be concerned about food safety, especially for dairy products. Our study confirms previous findings that consumers have higher levels of concern regarding food safety, including dairy products (Qiao et al., 2010; Zhang et al., 2010; Chen et al., 2013; Veeck et al., 2015). Notably, the participants with children or older people in their home were more likely to show concern about food safety in the dairy sector. Our findings are in line with the previous study that found that the respondents who had children are more concerned about milk safety (Gao et al., 2020).

Furthermore, consumers who live in different areas have a different perception of food safety in the dairy industry. Participants in the North group stressed the fact that they are concerned about food safety issues, but on the other hand, they expressed more optimistic views about food safety compared with participants in the South group. The results of the previous study provide a possible explanation for this finding that participants perceive local foods as being of a higher quality than imported foods (Chambers et al., 2007). In our study, participants in the North group linked the local dairy products to high quality and safety, because the region in which they live is one of the most important dairy production areas. Furthermore, unlike most of the other Chinese regions, Xinjiang has a long history of dairy cattle farming and milk consumption (Beldman et al., 2014).

Our results show that regarding the consumption of dairy products, chemical residues are the biggest concern for most consumers. Despite food safety incidents caused by chemical contamination being less frequent than those caused by microbial agents, toxic animal, or plant foods (Lam et al., 2013), it seems that consumers are more sensitive to chemical residues in the dairy sector. Part of the reason for this might be related to the infamous Sanlu infant formula milk powder incident, which is the most sensational one. Melamine, an industrial chemical, had been added to milk somewhere along with the supply chain, and 22 dairy companies were eventually implicated in the scandal. Although it has been more than a decade since it happened in 2008, consumers remember the incident.

\section{The Influence of Social Media on Consumers' Perception}

Due to frequently occurring food safety issues, consumers have increased attention to the reports related to food safety incidents in the media, which include social media such as blogs, microblogs, and direct messaging apps such as WeChat. This situation is consistent with the one described in a previous study, which concluded that food safety scandals revealed by the media could easily be noticed and remembered by consumers and further affect their judgments of expected utility and their purchasing behavior (Peng et al., 2015). However, it should be noted that false news has the same effect on consumers. There are constant reports about food safety, and some media hosted false reports published with the sole purpose of increasing traffic, especially on social media platforms such as Weibo and WeChat. Moreover, Chinese consumers find it very difficult to confirm the truthfulness of those reports because the response from the government or other official media is slow; most consumers choose to trust the adverse reports about food safety because they did not know how to identify the truth (Zhu et al., 2017). Another factor highlighted in the focus group discussion is that direct 
or indirect personal experience with food safety issues would affect consumers' confidence in food safety, as confirmed by the previous literature (Hansstein, 2015).

\section{Awareness About Traceable Food}

In the opinion of most participants, the possibility to trace back products at all stages of the dairy supply chain is considered essential. In line with the previous literature (Wang et al., 2013), consumers believe that tracking and tracing through all of the stages (from farm to table) can provide the information they want to know and will help them make the right purchasing choice. However, in our study, we found that traceable food is not very well known among the participants in these focus groups. Some of them had heard about it, but many participants mentioned that they had never bought traceable dairy products before. The main reasons given for the decision to buy or not to buy were incomprehension, distrust, inconvenience to purchase, and price. Similar to the study of Wu et al. (2015), consumers do not know about or trust traceability information.

\section{Credibility and Authenticity}

Despite the lack of awareness, providing consumers with food safety and quality information with the traceability system is considered important. Respondents were suspicious of the authenticity of traceability information, particularly when the traceable information was provided by enterprises but not certified by other third-party bodies, which may be of crucial importance to them. They are worried that the enterprises might falsify traceability information for their commercial interests. The traceability information certified by the government has more value for consumers than that certified by a third party. These results of the present study corroborate previous findings that consumers were dubious about the authenticity of traceability information, and a government certificate for traceability is currently valued more highly than certificates issued by a third party (Ortega et al., 2011; Hansstein, 2015).

Moreover, Bai et al. (2013) found a slightly different result in their study that although government-issued certification is still currently valued at the highest position, third-party certification for traceability food will become increasingly important in the future, and rising income and education are 2 driving forces. This finding has certain similarities with the conclusion of $\mathrm{Wu}$ et al. (2015) that consumers of different ages, education, and income level have different levels of trust in certification agencies. Young consumers with high education and income levels had a high relative willingness to pay for domestic third-party certification when purchasing traceable food.

\section{Cost of the Food Traceability System}

Regarding the issue of the cost for the establishment of a food traceability system, on one side, consumers stated that the government should be responsible for all or most of the cost. Others argued that enterprises should bear all the costs of establishing the food traceability system. Moreover, the stated price-premium for consumers on the purchase of traceable dairy products is in most cases quite low, people often indicate less than $10 \%$. That means government or enterprises should play an essential role in the implementation of the food traceability system. The result corroborates the previous finding of $\mathrm{Wu}$ et al. (2012), who found that if the price of certified traceable food is not acceptable or affordable to consumers, the implementation and promotion of a food traceability system will be difficult. Therefore, government funding support is critical for the implementation of food traceability systems.

\section{CONCLUSIONS}

The present study explored perceptions about the safety of dairy products and factors affecting consumers' purchasing decisions for dairy products, as well as consumers' attitudes toward traceable dairy products. Nine focus group interviews with 61 participants were carried out in 4 cities in 3 different provinces of China. Focus groups indicated that a high prevalence of food safety incidents lowers consumers' confidence in food safety and leads them to pay more attention to the news about food safety incidents in the media, including social media. Chemical residues were ranked as the first concern on food safety in the dairy industry. Traceable dairy products are not well known among consumers. Although the possibility to trace back all stages of the food supply chain in the dairy sector is considered necessary, consumers raise doubts about the authenticity of traceability information. In particular, they are not confident about traceability information provided by enterprises that have not been certified by third-party bodies. For the participants, the traceability information certified by the government has more value than the information certified by third-party agencies. Meanwhile, consumers suggest that the government should bear all or most of the cost of establishing the food traceability system. The study has some limitations that must be acknowledged. The research approach is qualitative and based on a small group of Chinese dairy consumers. The focus group interviews covered 2 different regions (Northwest and South of 
China), but cannot fully represent a wide and complex country such as China. The number of focus groups was limited to 9 because of budget constraints and because the researchers considered it a sufficient level of the emergence of new information. However, it is certainly possible that more insights could have been added if more discussions in other locations were organized. In any case, qualitative research is not based on representative samples, and its results cannot be generalized on the statistical point of view. However, the results can serve as a useful input for further research, and they provide a rich insight into consumer views of dairy products' safety problems in China. Some questions remain, such as what internal and external factors affect consumers' buying behavior and what consumers are willing to pay for traceable dairy products. A follow-up study based on a quantitative survey would be useful to attach a measure of relevance to the issues and aspects raised in this research.

\section{ACKNOWLEDGMENTS}

This work was financially supported by the Xinjiang Autonomous Region Humanities and Social Sciences Arid Area Rural Development Research Center Bidding Project (XJEDU030115C03). The authors thank the individuals who participated in the focus groups for openly sharing their thoughts and experiences. This research has been performed in partial fulfillment of the $\mathrm{PhD}$ project of the first author. The authors have not stated any conflicts of interest.

\section{REFERENCES}

Asioli, D., M. Canavari, E. Pignatti, T. Obermowe, K. L. Sidali, C. Vogt, and A. Spiller. 2014. Sensory experiences and expectations of Italian and German organic consumers. J. Int. Food Agribus. Mark. 26:13-27. https://doi.org/10.1080/08974438.2012.755718.

Bai, J., C. Zhang, and J. Jiang. 2013. The role of certificate issuer on consumers' willingness-to-pay for milk traceability in China. Agric. Econ. (UK) 44:537-544. https://doi.org/10.1111/agec.12037.

Beldman, A., J. Bai, B. Cao, Z. Cao, D. Wen, F. Xiangming, G. Huiyuan, G. Pei, H. Beizhong, H. Dinghuan, J. Heck, K. de Koning, L. Shengli, L. Montsma, L. Kai, L. Xiao, R. Fazheng, W. Wenxin, W. Yajing, X. Jianmin, and Y. Hongjian. 2014. White Paper on China Dairy. Beijing, P. R. of China. Accessed Jun. 2019. https:/ /edepot.wur.nl/334381.

Belk, R. W., E. Fischer, and R. V. Kozinets. 2013. Qualitative Consumer and Marketing Research.SAGE, London, UK.

Bruschi, V., K. Shershneva, I. Dolgopolova, M. Canavari, and R. Teuber. 2015. Consumer perception of organic food in emerging markets: Evidence from Saint Petersburg, Russia. Agribusiness 31:414-432. https://doi.org/10.1002/agr.21414.

Cappelli, L., F. D'Ascenzo, L. Natale, F. Rossetti, R. Ruggieri, and D. Vistocco. 2017. Are consumers willing to pay more for a "made in" product? An empirical investigation on "made in Italy." Sustainability 9:556. https://doi.org/10.3390/su9040556.

Chambers, S., A. Lobb, L. Butler, K. Harvey, and W. B. Traill. 2007. Local, national and imported foods: A qualitative study. Appetite 49:208-213. https://doi.org/10.1016/j.appet.2007.02.003.
Chan, K., T. Tse, D. Tam, and A. Huang. 2016. Perception of healthy and unhealthy food among Chinese adolescents. Young Consumers 17:32-45. https://doi.org/10.1108/YC-03-2015-00520.

Chen, T., M. Song, T. Nanseki, S. Takeuchi, H. Zhou, and D. Li. 2013. Consumer willingness to pay for food safety in Shanghai China: A case study of gap-certified milk. J. Fac. Agric. Kyushu Univ. $58: 467-473$

Cheng, L., S. Jiang, S. Zhang, H. You, J. Zhang, Z. Zhou, Y. Xiao, X. Liu, Y. Du, J. Li, X. Wang, Y. Xin, Y. Zheng, and K. Shang. 2016. Consumers' behaviors and concerns on fresh vegetable purchase and safety in Beijing urban areas, China. Food Control 63:101109. https://doi.org/10.1016/j.foodcont.2015.11.024.

Crovato, S., G. Mascarello, S. Marcolin, A. Pinto, and L. Ravarotto. 2019. From purchase to consumption of bivalve molluscs: A qualitative study on consumers' practices and risk perceptions. Food Control 96:410-420. https://doi.org/10.1016/j.foodcont.2018.09 .040 .

Cui, Y., L. Cacciolatti, Y. Liu, P., Woock, and X. Zhang. 2016. A qualitative exploratory investigation on the purchase intention of consumers affected by long-term negative advertising: A case from the Chinese milk sector. Economia Agro-Alimentare/Food Econ. 18:263-282. https://doi.org/10.3280/ECAG2016-003002.

Ding, H., Y. Fu, L. Zheng, and Z. Yan. 2017. 2018. Determinants of the competitive advantage of dairy supply chains: evidence from the Chinese dairy industry. Int. J. Prod. Econ. 1-14. https://doi .org/10.1016/j.ijpe.2018.02.013.

Feng, H., J. Feng, D. Tian, and W. Mu. 2012. Consumers' perceptions of quality and safety for grape products: A case study in Zhejiang Province, China. Br. Food J. 114:1587-1598. https://doi.org/10 .1108/00070701211273054.

Gao, Z., C. Li, J. Bai, and J. Fu. 2020. Chinese consumer quality perception and preference of sustainable milk. China Econ. Rev. 59:100939. https://doi.org/10.1016/j.chieco.2016.05.004.

Giselle, C. R., M. R. Susana, D. de Sousa Fernandes Douglas, A. de Araújo Gomes, P. H. Gonçalves Dias Dinizd Diniz, and C. V. Di Anibal. 2020. Qualitative and quantitative analysis based on digital images to determine the adulteration of ketchup samples with Sudan I dye. Food Chem. 328:127101. https://doi.org/10.1016/j foodchem.2020.127101.

Guest, G., E. Namey, and K. McKenna. 2017. How many focus groups are enough? Building an evidence base for nonprobability sample sizes. Field Methods 29:3-22. https://doi.org/10.1177/ $1525822 X 16639015$

Handford, C. E., K. Campbell, and C. T. Elliott. 2016. Impacts of milk fraud on food safety and nutrition with special emphasis on developing countries. Compr. Rev. Food Sci. Food Saf. 15:130-142. https://doi.org/10.1111/1541-4337.12181.

Hansstein, F. V. 2015. Consumer knowledge and attitudes towards food traceability: A comparison between the European Union, China and North America. Int. Proc. Chem. Biol. Environ. Eng. 51:139-142.

Hasimu, H., S. Marchesini, and M. Canavari. 2017. A concept mapping study on organic food consumers in Shanghai, China. Appetite 108:191-202. https://doi.org/10.1016/j.appet.2016.09.019.

Hinkes, C., and I. Christoph-Schulz. 2019. Consumer attitudes toward palm oil: Insights from focus group discussions. J. Food Prod. Mark. 25:875-895. https://doi.org/10.1080/10454446.2019 .1693468 .

Kendall, H., S. Kuznesof, M. Dean, M.-Y. Chan, B. Clark, R. Home, H. Stolz, Q. Zhong, C. Liu, P. Brereton, and L. Frewer. 2019. Chinese consumer's attitudes, perceptions and behavioural responses towards food fraud. Food Control 95:339-351. https://doi.org/10 .1016/j.foodcont.2018.08.006.

Lam, H.-M., J. Remais, M.-C. Fung, L. Xu, and S. S.-M. Sun. 2013. Food supply and food safety issues in China. Lancet 381:20442053. https://doi.org/10.1016/S0140-6736(13)60776-X.

Lichtman, M. 2014. Qualitative Research for the Social Sciences. Sage Publications, London, UK.

Lindberg, U., N. Salomonson, M. Sundström, and K. Wendin. 2018. Consumer perception and behavior in the retail foodscape-A study 
of chilled groceries. J. Retail. Consum. Serv. 40:1-7. https://doi .org/10.1016/j.jretconser.2017.09.001.

Morgan, D. L. 1996. Focus groups. Annu. Rev. Sociol. 22:129-152. https://doi.org/10.1146/annurev.soc.22.1.129.

Morgan, D. L., and R. A. Krueger. (1993). When to use focus groups and why. Pages 3-19 in Successful Focus Groups: Advancing the State of the Art. D. L. Morgan, ed. SAGE Publications, Thousand Oaks, CA. https://doi.org/https://doi.org/10.4135/ 9781483349008.n1

Nyumba, T. O., K. Wilson, C. J. Derrick, and N. Mukherjee. 2018. The use of focus group discussion methodology: Insights from two decades of application in conservation. Methods Ecol. Evol. 9:2032. https://doi.org/10.1111/2041-210X.12860.

Olsen, P., and M. Borit. 2013. How to define traceability. Trends Food Sci. Technol. 29:142-150. https://doi.org/10.1016/j.tifs.2012.10 .003 .

Ortega, D. L., H. H. Wang, L. Wu, and N. J. Olynk. 2011. Modeling heterogeneity in consumer preferences for select food safety attributes in China. Food Policy 36:318-324. https://doi.org/10.1016/ j.foodpol.2010.11.030.

Peng, Y., J. Li, H. Xia, S. Qi, and J. Li. 2015. The effects of food safety issues released by we media on consumers' awareness and purchasing behavior: A case study in China. Food Policy 51:44-52. https: //doi.org/10.1016/j.foodpol.2014.12.010.

Powell, R. A., and H. M. Single. 1996. Focus Groups. Int. J. Qual. Health Care 8:499-504. https://doi.org/10.1093/intqhe/8.5.499.

Qiao, G., T. Guo, and K. K. Klein. 2010. Melamine in Chinese milk products and consumer confidence. Appetite 55:190-195. https:// doi.org/10.1016/j.appet.2010.05.047.

Qing, P., F. X. Yan, and M. D. Wang. 2006. Consumer behaviour on green vegetable. Issues in Agric. Econ. 6:73-78.

Quan, S., Y. Zeng, and Y. Liu. 2011. Consumers risk perception and attitudes towards domestic and imported dairy products. Zhongguo Nongcun Guancha 2:2-16.

Roos, G. M., K. V. Hansen, and A. V. Skuland. 2016. Consumers, Norwegian food and belonging: A qualitative study. Br. Food J. 118:2359-2371. https://doi.org/10.1108/BFJ-01-2016-0041.

Song, Y. H., H. Q. Yu, and W. Lv. 2018. Risk analysis of dairy safety incidents in China. Food Control 92:63-71. https://doi.org/10 $.1016 /$ j.foodcont.2018.04.007.

Su, J. Y., and M. Canavari. 2018. Delphi Study on country-of-origin labeling for processed foods. Agric. Food Econ. 6:8. https://doi .org/10.1186/s40100-018-0103-7.

Threlfall, K. D. 1999. Using focus groups as a consumer research tool. J. Mark. Prac. Appl. Mark. Sci. 5:102-105. https://doi.org/10 .1108/EUM0000000004560.

Veeck, G., A. Veeck, and S. Zhao. 2015. Perceptions of food safety by urban consumers in Nanjing, China. Prof. Geogr. 67:490-501. https://doi.org/10.1080/00330124.2015.1028514.

Wang, Y., R. Wang, and W. Xiu. 2013. Beijing consumers' perception and willingness to pay for traceable labels on vegetables. Zhongguo Nongye Daxue Xuebao 18:215-222.

Wang, Z., Y. Mao, and F. Gale. 2008. Chinese consumer demand for food safety attributes in milk products. Food Policy 33:27-36. https://doi.org/10.1016/j.foodpol.2007.05.006.

Ward, M., and A. Inouye. 2018. China - Peoples republic of dairy and products semi-annual fluid milk consumption continues to increase. GAIN Report. USDA, Global Agricultural Information Network, Washington, DC.

Williams, E., B. Stewart-Knox, and I. Rowland. 2005. A qualitative analysis of consumer perceptions of mood, food and mood-enhanc- ing functional foods. J. Nutraceuticals Functional Med. Foods 4:61-83. https://doi.org/10.1300/J133v04n03 05.

Wu, L., X. Gong, S. Qin, X. Chen, D. Zhu, W. Hu, and Q. Li. 2017. Consumer preferences for pork attributes related to traceability, information certification, and origin labeling: Based on China's Jiangsu Province. Agribusiness 33:424-442. https://doi.org/10 $.1002 /$ agr.21509.

Wu, L., S. Wang, D. Zhu, W. Hu, and H. Wang. 2015. Chinese consumers' preferences and willingness to pay for traceable food quality and safety attributes: The case of pork. China Econ. Rev. 35:121-136. https://doi.org/10.1016/j.chieco.2015.07.001.

Wu, L., L. Xu, D. Zhu, and X. Wang. 2012. Factors affecting consumer willingness to pay for certified traceable food in Jiangsu Province of China. Can. J. Agric. Econ. 60:317-333. https://doi.org/10 .1111/j.1744-7976.2011.01236.x.

Wu, L., S. Yin, Y. Xu, and D. Zhu. 2014. Effectiveness of China's organic food certification policy: Consumer preferences for infant milk formula with different organic certification labels. Can. J. Agric. Econ. 62:545-568. https://doi.org/10.1111/cjag.12050.

Wu, X., Y. Lu, H. Xu, M. Lv, D. Hu, Z. He, L. Liu, Z. Wang, and Y. Feng. 2018. Challenges to improve the safety of dairy products in China. Trends Food Sci. Technol. 76:6-14. https://doi.org/10 .1016/j.tifs.2018.03.019.

Xu, P., S. Zheng, and M. Motamed. 2010. Perceived risks and safety concerns about fluid milk among Chinese college students. Agric Econ. (Czech Republic) 56:67-78. https://doi.org/10.17221/18/ 2009-AGRICECON.

Xu, P., J. Zhou, and T. Lone. 2016. Price acceptance for organic milk in Beijing, China. J. Food Prod. Mark. 22:752-766. https://doi .org/10.1080/10454446.2015.1121432.

Yin, S., Y. Li, Y. Xu, M. Chen, and Y. Wang. 2017. Consumer preference and willingness to pay for the traceability information attribute of infant milk formula: Evidence from a choice experiment in China. Br. Food J. 119:1276-1288. https://doi.org/10.1108/BFJ $-11-2016-0555$.

Zamawe, F. C. 2015. The implication of using NVivo software in qualitative data analysis: Evidence-based reflections. Malawi Med. J. 27:13-15. https://doi.org/10.4314/mmj.v27i1.4.

Zhang, C., J. Bai, B. T. Lohmar, and J. Huang. 2010. How do consumers determine the safety of milk in Beijing, China? China Econ. Rev. 21(Suppl. 1):S45-S54. https://doi.org/10.1016/j.chieco.2010 .05 .008 .

Zhang, C., J. Bai, and T. I. Wahl. 2012. Consumers' willingness to pay for traceable pork, milk, and cooking oil in Nanjing, China. Food Control 27:21-28. https://doi.org/10.1016/j.foodcont.2012.03.001.

Zhu, D., J. Cai, and W. Hongsha. 2013. Consumers' need of food safety information and willingness to pay-A study based on different safety information levels of traceable pork using the BDM mechanism. J. Public Manag. 10:129-143.

Zhu, H., P. Jackson, and W. Wang. 2017. Consumer anxieties about food grain safety in China. Food Control 73:1256-1264. https:// doi.org/10.1016/j.foodcont.2016.10.045.

Zhu, L., and Y. Xu. 2017. The study of consumers paid a premium for the food quality information label-Taking infant formula as an example. Price Theory Pract. 11:146-149.

Zinge, A., M.-E. Cousin, M. Connor, and M. Siegrist. 2013. Public risk perception in the total meat supply chain. J. Risk Res. 16:10051020. https://doi.org/10.1080/13669877.2013.788057. 